\title{
Mechanism of chemiluminescence in Fenton reaction
}

\author{
${ }^{1}$ Nizhny Novgorod State Medical Academy, Nizhny Novgorod, Russia \\ ${ }^{2}$ Skobeltsyn Institute of Nuclear Physics, Lomonosov Moscow State University, Moscow, Russia; \\ *Corresponding Author: i.m.piskarev@gmail.com \\ ${ }^{3}$ Nizhny Tagil Technological Institute Branch of Ural Federal University, Nizhny Tagil, Russia \\ ${ }^{4}$ Lobachevsky State University, Nizhny Novgorod, Russia
}

Irina Pavlovna Ivanova ${ }^{1}$, Svetlana Vladimirovna Trofimova ${ }^{1}$, Igor Mihailovich Piskarev ${ }^{2^{*}}$, Natalia Alekseevna Aristova ${ }^{3}$, Olga Evgenevna Burhina ${ }^{4}$, Oksana Olegovna Soshnikova ${ }^{4}$

Received 23 October 2011; revised 4 December 2011; accepted 16 December 2011

\begin{abstract}
A scheme of the processes in Fenton solution with various substances is offered, and the channels of light formation registered by the luminometer are analyzed. Under the proposed scheme we discuss the possibilities of studying the properties of antioxidants and prooxidants. Oxidation of alanine, albumin and sodium oxalate have been taken as an example. The properties of ascorbic acid and the mechanism of display of its oxidant and prooxidant properties are analyzed herewith. Methodical questions of the chemiluminescence research in Fenton solution such as the selection of reagents concentration, water preparation and the effect of the background radiation have been considered in this study as well.
\end{abstract}

Keywords: Fenton Reaction; Chemiluminescence; Oxidation Scheme; Antioxidant; Prooxidant

\section{INTRODUCTION}

Fenton reaction is widely used in the practice of scientific research as a source of hydroxyl radicals. Fenton reaction leads to the light radiation detected by modern luminometer. Secondary reactions initiated by the Fenton reagent are also often a source of photons. Recording these photons, we can obtain information about biophysical processes. A great number of papers have been written about bioluminescence and chemiluminescence [1-3]. Luminescence is enhanced with introduction of luminol, therefore the mechanism of luminol luminescence has been researched in detail [4]. With introduction of the Fenton reagent a flash of light is observed, that may last for several seconds to tens of minutes, although the duration of the Fenton reaction for the concentration of $\mathrm{Fe}^{2+}$ and $\mathrm{H}_{2} \mathrm{O}_{2}$, which are commonly used, can range from a few hours to many days [5]. New bursts of radiation are observed with a re-introduction into a solution of a fresh Fenton reagent. No research on formation of the mechanism of short bursts has been yet made.

The Fenton reaction is used to determine the antioxidant capacity of substances. One variant of the method is described here [6]. They measure the light sum of chemiluminescence of the Fenton reaction in the absence of the test substance $\mathrm{S} 0$ and the light sum in the presence of the test substance $\mathrm{S}$. If $\mathrm{S} 0=\mathrm{S}$, then we say that there are no antioxidant properties. If $\mathrm{S}<\mathrm{S} 0$, then the antioxidant properties are present. In this case, the anti-oxidant properties mean the ability of the test substance to be oxidized by hydroxyl radicals, to absorb them and thereby reduce the rate of hydroxyl radical reactions with other substances. The case when $\mathrm{S}>\mathrm{S} 0$ is also possible. Then we can say that the substance is prooxidant and enhances radical reactions.

It is interesting to investigate the general characteristics of reactions initiated by the Fenton reagent and leading to the formation of radiation in order to study the oxidative capability of various substances including medications. The processes occurring in a liquid environment are described by a great number of reactions between active particles and substances introduced to the solution. An analytical solution of the equations of chemical kinetics in this case is possible only if some strong simplifying assumptions with a highly restricted set of reactions are made. The solution is found by the method of stationary concentrations. This method gives a result related to a limited range of conditions and does not always have a general meaning. Therefore, we used numerical methods. We compiled a reactions scheme involving the formation of light radiation with a pure Fenton reagent, as well as the addition of luminol, inorganic and organic substances, one oxidation channel of which represents a chain reaction. 


\section{EXPERIMENTAL METHODS}

\subsection{Registration of Light}

A light emission was recorded by a chemiluminometer BCh-06 (N. Novgorod, Russia). Spectral range sensitivity of the photomultiplier (PM) is $400-700 \mathrm{~nm}$. A calibration of the device was performed via the reference light source of the known intensity. When recording the light from the sample, the measurement of the noise of the registering device, that was made automatically, was performed directly before and immediately after each measurement. The lower detection limit of the light radiation is determined by fluctuations of the noise. The measurements showed that the mean-square fluctuations of the noise ranged from 200 to 500 pulses per second depending on the device condition. Thus the minimum detectable effect was about 200 photons per second. The sample volume was $1.0 \mathrm{ml}$. The composition of the sample was as follows: $0.4 \mathrm{ml}$ of $\mathrm{FeSO}_{4}, 0.4 \mathrm{ml}$ of the test substance, $0.2 \mathrm{ml}$ of hydrogen peroxide. The reactant concentration was $\left[\mathrm{FeSO}_{4}\right]=10^{-3} \mathrm{~mol} / \mathrm{l},\left[\mathrm{H}_{2} \mathrm{O}_{2}\right]=10^{-4}$ $\mathrm{mol} / \mathrm{l}$. A cuvette containing the sample was located very closely to the PM photocathode ensuring high detection efficiency (solid angle $\Omega=\pi$ ). The cuvette was firstly injected with a solution of ferrous iron, the substance under investigation, and last of all peroxide. A solution of hydrogen peroxide of a necessary concentration for the Fenton reagent had been prepared in advance, while a solution of $\mathrm{FeSO}_{4}$ - right before the commencement of the experiment. The registration of radiation began in 0.5 1 second after mixing the sample solution containing $\mathrm{FeSO}_{4}$ with peroxide. This time is required to add the peroxide and switch the device to the mode of measuring the intensity of chemiluminescence. Analytical grade reagents, double-distilled and only distilled water $(\mathrm{pH} 6)$ were used for the experiment.

\subsection{Preparation of Water}

Preparation of water for these experiments is of great importance. First of all the sameness of water contents is crucial. Even the water Milli-Q, Milli-pore, standing in the air, absorbs carbon dioxide. Its properties will depend on how much time the water was the subject to contact with the air after the preparation. Accumulated in the water under absorption of carbon dioxide hydrocarbons react with the hydroxyl radicals generated in the Fenton reaction, thereby reducing their concentration. The calculation in the scope of the model used in this study shows that the concentration $\left[\mathrm{HCO}_{3}^{-}\right]=10^{-7} \mathrm{~mol} / \mathrm{l}$ does not affect the consumption of $\mathrm{OH}^{-}$radicals. However, when $\left[\mathrm{HCO}_{3}^{-}\right] \geq 10^{-6} \mathrm{~mol} / 1$ hydrocarbons absorb a significant amount of hydroxyl radicals, which affect the results of the experiment. The calculation results have been confirmed by the experiment. Therefore we used only freshly prepared distilled water. To monitor the stability of the water composition the chemiluminescence light sum for the pure Fenton solution prepared with this water was measured.

The chemiluminescence light sum was registered during 30 seconds. Every point was measured in $10-12$ repetitions. Cleanliness of the solutions, the composition of the reaction products were controlled at various stages by monitoring the UV spectra with the spectrophotometer Fluorat-02 Panorama. The spectral characteristics of the light radiation from water was qualitatively evaluated using color filters of blue and red plastic films with a thickness of $0.5 \mathrm{~mm}$. The transmission spectrum of the films was measured by the spectrophotometer Fluorat-02 Panorama. The bandwidth of the blue filter at least $10 \%$ of the maximum transparency was ranging from 410 to $590 \mathrm{~nm}$, red-from 590 to $750 \mathrm{~nm}$. The films that do not give the secondary radiation in the visible spectrum were sorted out.

\section{RESULTS AND DISCUSSION}

\subsection{Kinetic Model of the Process}

The model of the process included the Fenton reaction, the interaction of radicals, the products of this reaction, the formation and de-excitation of the singlet oxygen. The scheme of the reaction is presented in Table 1. The reaction rate constants are given in the references [7]. The concentrations of ions $\mathrm{OH}^{-}$и $\mathrm{H}^{+}$( $\mathrm{pH}$ of solution) are set as coefficients. The model includes the interaction of ferrous iron with hydrogen peroxide and subsequent formation of radicals $\mathrm{OH}^{\circ}, \mathrm{HO}_{2}^{\bullet}, \mathrm{O}_{2}^{--}$and singlet oxygen, the dissociation of hydrogen peroxide $\mathrm{H}_{2} \mathrm{O}_{2} \leftrightarrow$ $\mathrm{HO}_{2}^{-}+\mathrm{H}^{+}, \mathrm{pK}_{\mathrm{a}}=11.5$ (reactions 12,13 ) and the equilibrium $\mathrm{HO}_{2}^{\circ} \leftrightarrow \mathrm{H}^{+}+\mathrm{O}_{2}^{\bullet-}, \mathrm{pK}_{\mathrm{a}}=4.8$ (the 7,8). It was assumed that in the neutral and alkaline medium ferrous and ferric irons precipitate (reactions 15, 16, Table 1.) Air usually contains carbon dioxide and it is absorbed by water. The existence of hydrocarbons was taken into account (reactions 18 - 20). The external ionizing radiation (background and cosmic rays) caused radiolysis of water. The yield of the radiolysis products and their reactions are known [8]. These reactions are included in the calculation scheme (Table 1). The system of equations of chemical kinetics was solved using a package MathCad 14. The purpose of the numerical simulation was to evaluate the contribution of specific mechanisms and to analyze the concentration of active species (radicals and molecular products). These data are necessary for the quantitative analysis of free radical products formed in biological systems during the development of pathological processes and after the action of physical and chemical factors. 
Table 1. The rate constants for reactions in Fenton solution.

\begin{tabular}{|c|c|c|}
\hline No & Reaction & $\mathrm{k}, \mathrm{l} /(\mathrm{mol} \cdot \mathrm{s}),[7]$ \\
\hline & $\mathrm{Fe}^{2+}+\mathrm{H}_{2} \mathrm{O}_{2} \rightarrow \mathrm{Fe}^{3+}+\mathrm{OH}^{\bullet}+\mathrm{OH}^{-}$ & $\mathrm{k}_{1}=56$ \\
\hline & $\mathrm{OH}^{\bullet}+\mathrm{H}_{2} \mathrm{O}_{2} \rightarrow \mathrm{HO}_{2}^{\bullet}+\mathrm{H}_{2} \mathrm{O}$ & $\mathrm{k}_{2}=3 \times 10^{7}$ \\
\hline & $\begin{array}{l}\mathrm{HO}_{2}^{\bullet}+\mathrm{HO}_{2}^{\bullet} \rightarrow \mathrm{H}_{2} \mathrm{O}_{2}+\mathrm{O}_{2}+ \\
\mathrm{O}_{2}\left(\mathrm{a}^{1} \Delta_{\mathrm{g}}\right)\end{array}$ & $\mathrm{k}_{3}=8.3 \times 10^{5}$ \\
\hline & $\mathrm{Fe}^{2+}+\mathrm{OH}^{\bullet} \rightarrow \mathrm{Fe}^{3+}+\mathrm{OH}^{-}$ & $\mathrm{k}_{4}=3 \times 10^{8}$ \\
\hline & $\mathrm{OH}^{\bullet}+\mathrm{OH}^{\bullet} \rightarrow \mathrm{H}_{2} \mathrm{O}+\frac{1}{2}\left(\mathrm{O}_{2}+\mathrm{O}_{2}\left(\mathrm{a}^{1} \Delta_{\mathrm{g}}\right)\right)$ & $\mathrm{k}_{5}=5.5 \times 10^{9}$ \\
\hline & $\mathrm{OH}^{\bullet}+\mathrm{HO}_{2}^{\bullet} \rightarrow \mathrm{H}_{2} \mathrm{O}+\mathrm{O}_{2}+\mathrm{O}_{2}\left(\mathrm{a}^{1} \Delta_{\mathrm{g}}\right)$ & $\mathrm{k}_{6}=7.1 \times 10^{9}$ \\
\hline & $\mathrm{HO}_{2}^{\cdot} \rightarrow \mathrm{H}^{+}+\mathrm{O}_{2}^{-}$ & $\mathrm{k}_{7}=7.5 \times 10^{6}, \mathrm{pK}_{\mathrm{a}}=4.8$ \\
\hline & $\mathrm{H}^{+}+\mathrm{O}_{2}^{--} \rightarrow \mathrm{HO}_{2}^{\cdot}$ & $\mathrm{k}_{8}=5.1 \times 10^{10}$ \\
\hline & $\mathrm{HO}_{2}^{-}+\mathrm{O}_{2}^{--} \rightarrow \mathrm{HO}_{2}^{-}+\mathrm{O}_{2}$ & $\mathrm{k}_{9}=9.7 \times 10^{7}$ \\
\hline & $\mathrm{HO}_{2}^{\bullet}+\mathrm{OH}^{-} \rightarrow \mathrm{O}_{2}^{--}+\mathrm{H}_{2} \mathrm{O}$ & $\mathrm{k}_{10}=10^{10}$ \\
\hline & $\mathrm{O}_{2}^{--}+\mathrm{Fe}^{3+} \rightarrow \mathrm{Fe}^{2+}+\mathrm{O}_{2}$ & $\mathrm{k}_{11}=1.9 \times 10^{9}$ \\
\hline & $\mathrm{H}_{2} \mathrm{O}_{2} \rightarrow \mathrm{HO}_{2}^{-}+\mathrm{H}^{+}$ & $\mathrm{k}_{12}=2 \times 10^{-2}$ \\
\hline & $\mathrm{HO}_{2}^{-}+\mathrm{H}^{+} \rightarrow \mathrm{H}_{2} \mathrm{O}_{2}$ & $\mathrm{k}_{13}=10^{10}, \mathrm{pK}_{\mathrm{a}}=11.5$ \\
\hline & $\mathrm{OH}^{\bullet}+\mathrm{HO}_{2}^{-} \rightarrow \mathrm{HO}_{2}^{\cdot}+\mathrm{OH}^{-}$ & $\mathrm{k}_{14}=7.5 \times 10^{9}$ \\
\hline & $\mathrm{Fe}^{3+}+3 \mathrm{OH}^{-} \rightarrow \mathrm{Fe}(\mathrm{OH})_{3}$ & $\mathrm{k}_{15}=10^{6}, \mathrm{pH}=12$ \\
\hline & $\mathrm{Fe}^{2+}+2 \mathrm{OH}^{-} \rightarrow \mathrm{Fe}(\mathrm{OH})_{2}$ & $\mathrm{k}_{16}=10^{6}, \mathrm{pH}=12$ \\
\hline & $\mathrm{H}_{2} \mathrm{O}_{2}+\mathrm{O}_{2}^{--} \rightarrow \mathrm{OH}^{-}+\mathrm{OH}^{\bullet}+\mathrm{O}_{2}$ & $\mathrm{k}_{17}=16$ \\
\hline & $\mathrm{HCO}_{3}^{-}+\mathrm{OH}^{\bullet} \rightarrow \mathrm{CO}_{3}^{--}+\mathrm{H}_{2} \mathrm{O}$ & $\mathrm{k}_{18}=4 \times 10^{7}$ \\
\hline & $\mathrm{CO}_{3}^{--}+\mathrm{OH}^{\bullet} \rightarrow \mathrm{CO}_{2}+\mathrm{HO}_{2}^{-}$ & $\mathrm{k}_{19}=3 \times 10^{9}$ \\
\hline & $\mathrm{CO}_{3}^{--}+\mathrm{H}_{2} \mathrm{O}_{2} \rightarrow \mathrm{HCO}_{3}^{-}+\mathrm{HO}_{2}^{-}$ & $\mathrm{k}_{20}=8 \times 10^{5}$ \\
\hline
\end{tabular}

The rate constant for each reaction is known to have some errors. Various sources provide different values. With a large number of reactions that simultaneously take place in the system, changes in the reaction constants over a wide range do not lead to noticeable changes in results. This is due to the fact that in the chain of the sequential and parallel transformation the variation in the reaction constants make the concentration of the intermediate products also change. If the rate of consumption of the intermediate product is reduced, its concentration increases. As a result, the rate of the final product formation may not change at all.

\subsection{The Mechanism of Luminescence of Fenton Solution}

The reactions in the water involving reactive oxygen species, initiated by the Fenton reagent, lead to luminescence registered by BCh- 06 . The spectral composition of the light radiation was estimated with red and blue filters. We have established that the blue filter reduces the emission by more than 10 times, while the red filter does not change the light intensity.

A dimer of singlet oxygen might be used for luminescence in this spectral region. The formation and decay scheme of the singlet oxygen is shown in Table 2.

Luminescence is recorded if the sample contains the reaction products in an excited state. Almost all of the reaction products that are listed in Tables 1 and $\mathbf{2}$ can form excited states displayed in the UV spectrum (wavelength below $400 \mathrm{~nm}$ ). But its radiation is out of spectral sensitivity of the PM photocathode. In the red region of the spectrum only a dimer of the singlet oxygen can be displayed $(\lambda=480,535$ and $580 \mathrm{~nm})$ [1-3].

The mechanisms of the singlet oxygen formation were analyzed. The spin selection rules allow the formation both a singlet and a triplet oxygen in the reactions $(3,5$, 6. Table 1). Ratio of probabilities of the singlet and triplet states production is determined by the rules of quantum mechanics and is equal to 1:3. Only singlet oxygen can be formed in the reactions $(21,22$, Table 2$)$. The calculation showed that the yield of $\mathrm{O}_{2}\left(\mathrm{a}^{1} \Delta_{\mathrm{g}}\right)$ in the reactions $(3,5,6)$ is small because the concentration of radicals $\mathrm{HO}_{2}^{*}$ and $\mathrm{OH}^{\bullet}$ is small.

Therefore, reactions with a radical $\mathrm{O}_{2}^{\cdot-}(21,22)$ are the basic mechanism of the singlet oxygen formation. The source of $\mathrm{O}_{2}^{--}$is radicals $\mathrm{HO}_{2}^{\cdot}$ (reactions 7 and 10). The final luminescent product is a singlet oxygen (more definitely, a dimer of the singlet oxygen). A dimer decomposes almost instantaneously, so the intensity of emission is determined by the rate of its formation. This is not a rate of one single reaction, but a total (resultant) rate of the whole sequence (chain) of reactions, which ends with the formation of the singlet oxygen dimer. In case of a Fenton reagent ferric ion, formed in solution, reacts with $\mathrm{O}_{2}^{--}$(reaction 11, Table 1), which significantly reduces the concentration of these particles. With decreasing the concentration of $\mathrm{O}_{2}^{--}$the yield of the singlet oxygen decreases, so in Fenton solution a short burst of radiation is always observed immediately after mixing the reagents, the duration of which significantly smaller than the total reaction time at these concentra-

Table 2. Formation and decay of singlet oxygen.

\begin{tabular}{lll}
\hline No & \multicolumn{1}{c}{ Reaction } & \multicolumn{1}{c}{$\mathrm{k},(\mathrm{mol} \cdot \mathrm{s})^{-1}[9]$} \\
\hline 21. & $\mathrm{O}_{2}^{\bullet-}+\mathrm{OH}^{\bullet}+\mathrm{H}^{+} \rightarrow \mathrm{H}_{2} \mathrm{O}+\mathrm{O}_{2}\left(\mathrm{a}^{1} \Delta_{\mathrm{g}}\right)$ & $\mathrm{k}_{21}=10^{10}$ \\
22. & $\mathrm{O}_{2}^{--}+\mathrm{H}^{+} \rightarrow \frac{1}{2} \mathrm{H}_{2} \mathrm{O}_{2}+\frac{1}{2} \mathrm{O}_{2}\left(\mathrm{a}^{1} \Delta_{\mathrm{g}}\right)$ & $\mathrm{k}_{22}=10^{10}$ \\
23. & Decay $\mathrm{O}_{2}\left(\mathrm{a}^{1} \Delta_{\mathrm{g}}\right)$ & $\tau_{1 / 2}=2.9 \times 10^{-4} \mathrm{c}$ \\
24. & $\mathrm{O}_{2}\left(\mathrm{a}^{1} \Delta_{\mathrm{g}}\right)+\mathrm{O}_{2}\left(\mathrm{a}^{1} \Delta_{\mathrm{g}}\right) \rightarrow 2 \mathrm{O}_{2}+\gamma$ & $\mathrm{k}_{24}=0.1$ \\
25. & $\mathrm{O}_{2}\left(\mathrm{a}^{1} \Delta_{\mathrm{g}}\right)+\mathrm{O}_{2}\left(\mathrm{a}^{1} \Delta_{\mathrm{g}}\right) \rightarrow$ products & $\mathrm{k}_{25}=10^{11}$ \\
\hline
\end{tabular}


tions of reagents [5]. When there are no ferric ions in solution, ion-radicals $\mathrm{O}_{2}^{\bullet-}$ accumulate, and the number of the generated singlet oxygen molecules increases. The lifetime of the singlet oxygen in water with low concentrations of impurities is approximately 40 minutes. The probability of the dimer formation is about 1000 times higher than the spontaneous decay [9]. The calculation showed that the quenching of the singlet oxygen on the vessel walls and in the reactions with other particles is negligible. With the increasing concentration of $\mathrm{O}_{2}\left(\mathrm{a}^{1} \Delta_{\mathrm{g}}\right)$ the reaction 25 (Table 2), the products of which do not give the radiation in the visible light spectrum, plays a decisive role in their deaths. The kinetics of changes in the concentration of radicals after addition of a Fenton reagent is described [5].

To sum up, immediately after mixing the components of the Fenton reagent no ferric iron has yet been formed in the solution, and all nascent $\mathrm{O}_{2}^{--}$radicals are consumed on the singlet oxygen production. Therefore, immediately after mixing a maximum light emission is observed. Ferric iron that is being formed begins to consume radicals $\mathrm{O}_{2}^{\bullet-}$, luminescence is decreased, and stops if the concentration of $\mathrm{Fe}^{3+}$ obtains high concentrations, capturing all $\mathrm{O}_{2}^{\bullet-}$ radicals. Thus, the light flash duration is not determined by the consumption of the reagents in the Fenton reaction, but it is determined by the time that is sufficient to form a large number of $\mathrm{Fe}^{3+}$ ions. Luminescence in this case is in the red region of the light spectrum.

\subsection{The Selection of Peroxide Concentration}

The peculiarity of the chemiluminometer BCh-06 is that the optimal time of the registration light emission in terms of high stability is 30 seconds. It is reasonable to choose the concentration of reactants to make the time of the Fenton reaction also about $30 \mathrm{sec}$. According to the study results [5], when $\left[\mathrm{Fe}^{2+}\right]=10^{-3} \mathrm{~mol} / \mathrm{l}$ and $\left[\mathrm{H}_{2} \mathrm{O}_{2}\right]=$ $10^{-4} \mathrm{~mol} / \mathrm{l}$ the time of the reducing reaction rate up to $1 \%$ of its initial value is 60 seconds. In practice, the concentrations of $\left[\mathrm{Fe}^{2+}\right]=10^{-3} \mathrm{~mol} / 1$ and $\left[\mathrm{H}_{2} \mathrm{O}_{2}\right]=10^{-1} \mathrm{~mol} / \mathrm{l}$ are commonly used [10]. We compare these two concentrations. First of all, the concentration of hydrogen peroxide under other equal conditions affects the duration and amplitude of the leading edge of the light flash. The calculated values of the light sum $\mathrm{S}$ on the time in the range of 0.01 to 30 seconds for the concentration of $\left[\mathrm{H}_{2} \mathrm{O}_{2}\right]=10^{-1}$ and $10^{-4} \mathrm{~mol} / \mathrm{l}$ are presented in Figure 1. A step on the time axis is 0.01 seconds. We see that when $\left[\mathrm{H}_{2} \mathrm{O}_{2}\right]=10^{-1} \mathrm{~mol} / \mathrm{l}$ at the beginning of the reaction there is a short light flash with a duration of less than $0.1 \mathrm{sec}-$ onds and a large amplitude and almost all the photons are emitted. During the time from 0.1 to 30 seconds, the light sum increases slowly. The loss of photons emitted for 0 0.5 seconds (time delay of registration) reduces the registered light sum by $100-1000$ times. At $\left[\mathrm{H}_{2} \mathrm{O}_{2}\right]=10^{-4}$ $\mathrm{mol} / \mathrm{l}$ the light sum increases slowly, the loss of radiation at $\mathrm{t}<0.5$ seconds has a little effect on the outcome. Since it is impossible to begin the registration of the light radiation in less than 0.5 seconds after the last injection of the reagent, when $\left[\mathrm{H}_{2} \mathrm{O}_{2}\right]=10^{-1} \mathrm{~mol} / \mathrm{l}$ the largest and uncontrollable part of the radiation remains unregistered. The situation is aggravated by the fact that the time for mixing the solution after the introduction of peroxide at the final stage is not equal to zero. The introduced peroxide has a concentration of up to 5 times greater than

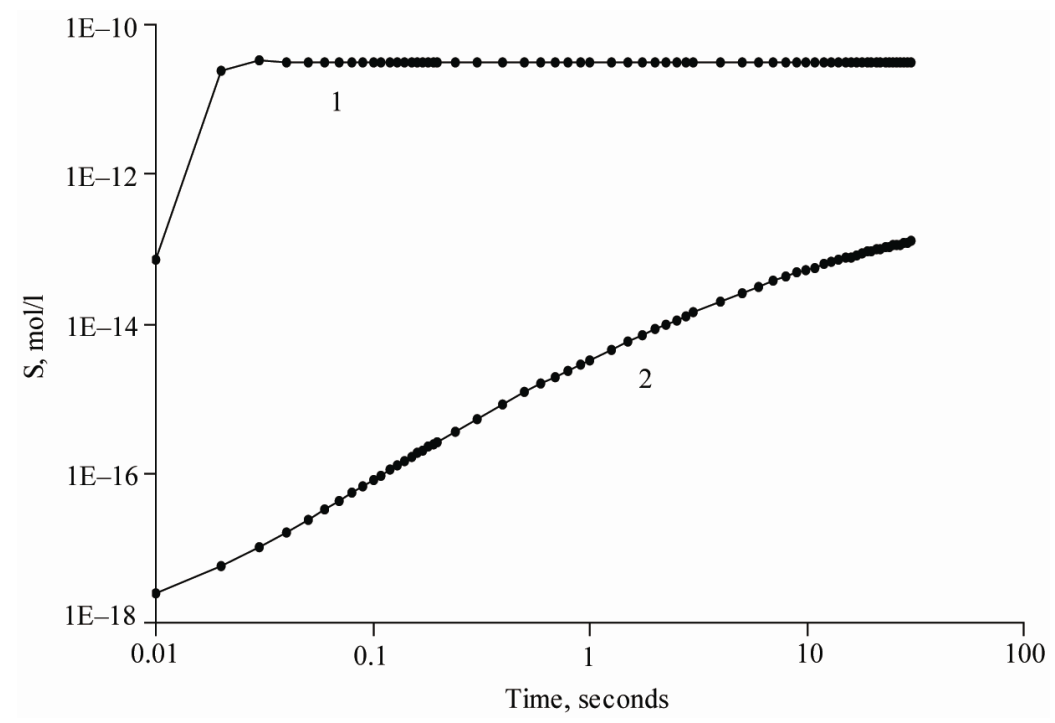

Figure 1. Time dependence of the total number of emitted photons, the light sum $\mathrm{S}$, on the time since mixing the reagents for the concentration of $\left[\mathrm{Fe}^{2+}\right]=10^{-3}$ $\mathrm{mol} / \mathrm{l}$ and $\left[\mathrm{H}_{2} \mathrm{O}_{2}\right]=10^{-1} \mathrm{~mol} / \mathrm{l}(1)$ and $10^{-4} \mathrm{~mol} / \mathrm{l}(2)$. 
that averaged by the volume, and the reaction starts immediately after the contact with the tested solution. In this case the front of the light flash will be even shorter. The homogeneity of the solution is of high importance. When the concentration of $\left[\mathrm{H}_{2} \mathrm{O}_{2}\right]=10^{-4} \mathrm{~mol} / \mathrm{l}$ the light flash front is significantly longer.

Therefore, the delay of start registration, the quality of mixing the tested solution and the diffusion time of the peroxide from the introduced drop into the full volume affect the result significantly less. An uncontrolled systematic error of the measurement will be significantly less than that in the previous case.

The use of the Fenton reagent components concentrations $\left[\mathrm{Fe}^{2+}\right]=10^{-3} \mathrm{~mol} / \mathrm{l}$ and $\left[\mathrm{H}_{2} \mathrm{O}_{2}\right]=10^{-4} \mathrm{~mol} / 1$ provides more reliable results than those with a high concentration of peroxide, therefore we selected these concentrations.

\subsection{The Yield of Water Radiolysis Products Created by the Background Radiation}

The power of the dose produced by the background radiation is known to be determined by cosmic radiation and other factors. It ranges from 0.05 to $0.3 \mu \mathrm{Sv} / \mathrm{h}$ with an average value of $0.12 \mu \mathrm{Sv} / \mathrm{h}$. In water the radiation creates products of radiolysis. The yields of the primary products of radiolysis at $\mathrm{pH} 7$ are presented in Table 3 .

The yield of radicals are calculated for an average radiation background of $0.12 \mu \mathrm{Sv} / \mathrm{h}$. This corresponds to the energy released in 1 liter of water, $2.06 \times 10^{8} \mathrm{eV} / \mathrm{s}$. Formed in the radiolysis the particles with reducing properties (hydrated electron and atomic hydrogen) interact with the oxygen dissolved in water, forming radi- cals $\mathrm{O}_{2}^{--}$and $\mathrm{HO}_{2}^{\bullet}[8]$

\subsection{Stationary Concentration of the Radiolysis Products}

Under the constant influence of the radiation background the radiolysis products accumulate and establish their steady-state concentration. A steady-state concentration depends on the level of the background radiation. Table 4 shows the calculated steady-state concentrations of the short-lived products and the time required to establish steady-state concentrations. The time for establishing a steady-state concentration depends on the level of the background radiation. Active particles cumulated under the action of the background radiation cause the solution chemiluminescence. In Table 4 the calculated values of the photon yield for 30 seconds are also presented.

Under the action of the background radiation hydrogen peroxide accumulates both through the direct formation by radiation (Table 3 ) and in reactions with radicals (reaction 3 and 19). In the reaction of the bicarbonate with hydroxyl radicals ion-radicals $\mathrm{CO}_{3}^{--}$are initially formed. Then they again react with hydroxyl radicals, forming a product of dissociation of hydrogen peroxide, $\mathrm{HO}_{2}^{-}$and carbon dioxide. Thus, the bicarbonates influence the concentration of hydrogen peroxide. A stationary concentration of peroxide at different levels of the background radiation and different concentrations of the bicarbonate are presented in Table 5. The presence of ferrous iron in the solution does not affect the steady-state concentration of peroxide up to $\left[\mathrm{Fe}^{2+}\right]=10^{-8} \mathrm{~mol} / \mathrm{l}$. At higher concentrations of iron the concentration of perox-

Table 3. The yield of the primary products of radiolysis at $\mathrm{pH} 7$ [8].

\begin{tabular}{cccccc}
\hline Product & $\mathrm{e}_{\mathrm{aq}}^{-}$ & $\mathrm{H}^{\bullet}$ & $\mathrm{OH}^{\bullet}$ & $\mathrm{H}_{2} \mathrm{O}_{2}$ & $\mathrm{H}_{2}$ \\
\hline Yield at $100 \mathrm{eV}$ & 2.8 & 0.5 & 2.8 & 0.7 & 0.45 \\
Converted into radicals & $\mathrm{O}_{2}^{-}$ & $\mathrm{HO}_{2}^{-}$ & - & - & - \\
Yield mol $/(1 \cdot \mathrm{s})$ & $9.5 \times 10^{-18}$ & $1.7 \times 10^{-18}$ & $9.5 \times 10^{-18}$ & $2.4 \times 10^{-18}$ & $1.53 \times 10^{-18}$ \\
\hline
\end{tabular}

Table 4. The stationary concentration of the active particles formed in the water under the influence of background radiation (calculated).

\begin{tabular}{ccccc}
\hline \multirow{2}{*}{ The product of radiolysis } & \multicolumn{2}{c}{ Concentration, mol/l at different levels of background radiation } & \multirow{2}{*}{$1.2 \mu \mathrm{Sv} / \mathrm{h}$} & The time for establishing steady-state concentration, $\mathrm{s}$ \\
\cline { 2 - 4 } & $0.012 \mu \mathrm{Sv} / \mathrm{h}$ & $0.12 \mu \mathrm{Sv} / \mathrm{h}$ & $1.9 \times 10^{-14}$ & $100-200$ \\
\hline $\mathrm{O}_{2}^{-}$ & $1 \times 10^{-16}$ & $1.4 \times 10^{-15}$ & $8 \times 10^{-15}$ & $1000-1500$ \\
$\mathrm{O}_{2}\left(\mathrm{a}^{1} \Delta_{\mathrm{g}}\right)$ & $7 \times 10^{-16}$ & $2.4 \times 10^{-15}$ & $10^{-22}$ & 1 \\
$\mathrm{OH}^{\cdot}$ & $10^{-24}$ & $10^{-23}$ & $3 \times 10^{-24}$ & 1 \\
$\mathrm{HO}_{2}$ & $2 \cdot 10^{-26}$ & $3 \times 10^{-25}$ & &
\end{tabular}

Luminescence for $30 \mathrm{sec} \quad 2 \times 10^{-16} \mathrm{~mol} / 1 \quad 4.7 \times 10^{-16} \mathrm{~mol} / 1 \quad 2.1 \times 10^{-15} \mathrm{~mol} / 1 \quad$ Not less than 20 minutes 
Table 5. The stationary concentration of hydrogen peroxide formed in the water under the influence of background radiation (calculated). The estimated time for the steady-state concentration is $10^{7}$ seconds.

\begin{tabular}{cccc}
\hline \multirow{2}{*}[\mathrm{HCO}_{3}^{-}]{$(\mathrm{mol} / \mathrm{l})$} & \multicolumn{2}{l}{$\left[\mathrm{H}_{2} \mathrm{O}_{2}\right](\mathrm{mol} / \mathrm{l})$ at various levels of background } \\
& radiation & & \\
\cline { 2 - 4 } & $0.012 \mu \mathrm{Sv} / \mathrm{h}$ & $0.12 \mu \mathrm{Sv} / \mathrm{h}$ & $1.2 \mu \mathrm{Sv} / \mathrm{h}$ \\
\hline $10^{-2}$ & $2.5 \times 10^{-11}$ & $2.3 \times 10^{-10}$ & $2.5 \times 10^{-9}$ \\
$10^{-3}$ & $2.5 \times 10^{-11}$ & $2.3 \times 10^{-10}$ & $2.3 \times 10^{-9}$ \\
0 & $1.1 \times 10^{-11}$ & $8 \times 10^{-11}$ & $6.2 \times 10^{-10}$ \\
\hline
\end{tabular}

ide decreases.

\subsection{Scheme of the Oxidation by Radicals Generated in the Fenton Reaction with the Formation of Luminous Products}

The mechanisms of luminescence of Fenton solution in a neutral solution $(\mathrm{pH} \sim 7)$ are analyzed for the following cases:

1) solution of Fenton (no other chemicals are introduced);

2) addition of luminol;

3) ideal antioxidant M (a substance capable of oxidation);

4) addition of organic substance RH, which can develop a chain reaction of oxidation:

a) a substance capable of forming radicals $\mathrm{RO}_{2}^{\bullet}$ (with availability of oxygen);

b) a substance that generates only radicals $\mathrm{R}^{\bullet}$ (with a lack of oxygen). Channels reactions are conditionally presented in Scheme 1 and numbered.

Case 1. Pure Fenton solution. Scheme 1, channel 1. The reaction products are ferric ions and hydroxyl radicals $\mathrm{OH}^{\bullet}$. A luminescence mechanism has already been shown (see Tables 1 and 2). The sequence of reactions of radicals can be represented as follows: $\mathrm{OH}^{\bullet} \rightarrow \mathrm{HO}_{2}^{\bullet} \rightarrow$ $\mathrm{O}_{2}^{\cdot-} \rightarrow \mathrm{O}_{2}\left(\mathrm{a}^{1} \Delta_{\mathrm{g}}\right)$. A luminiscence of the dimer of singlet oxygen is in the red spectrum $(\lambda=480,535$ and $580 \mathrm{~nm})$. Luminescence duration is not determined by spending the reagents in the Fenton reaction, but by the time required to attain a sufficiently large number of ions $\mathrm{Fe}^{3+}$ that use $\mathrm{O}_{2}^{\bullet-}$ radicals and thus cease to glow.

Case 2. Luminescence with luminol in a neutral medium. Scheme 1, channel 2. Luminol Lum reacts with a hydroxyl radical, forming radical $\mathrm{L}^{\bullet}$. This radical reacts with superoxide radicals $\mathrm{O}_{2}^{--}$, and after a chain of reactions, conditionally presented in the scheme by two crosses, luminescence of a quantum in the blue spectral region appears $[3,4]$. This is the case as long as there is no ferric iron. When ions $\mathrm{Fe}^{3+}$ appears, the radical $\mathrm{O}_{2}^{\bullet-}$ is consumed in the reaction with $\mathrm{Fe}^{3+}$. In this case the blue glow decreases, and fully stops with high concentrations of $\mathrm{Fe}^{3+}$. But with low concentrations of ferric iron the luminescence covers the blue spectral region (luminol) and the red one (dimer of singlet oxygen), since luminol does not intercept all the produced hydroxyl radicals. The luminol-dependent luminescence of Fenton solution in a neutral solution is considered in more detail in [5].

Case 3. An ideal antioxidant $\mathbf{M}$ is the substance oxidized by radicals. The reaction products are low-active radicals not capable to participate in further conversions with a considerable rate. In this case, the hydroxyl radicals are consumed in its oxidation. If the reaction rate $\mathrm{M}$ $+\mathrm{OH}^{\bullet}$ is much greater than that of in channel 1 , no light emission will occur. When the rate of consumption of $\mathrm{OH}^{\bullet}$ radicals in the processes 1 and 3 are comparable, the luminescence will be observed in the red spectrum. With increasing concentration of substance M luminescence will diminish until it completely disappears. The dependence of the light sum for 30 seconds on the concentration of introduced material $\mathrm{M}$ is shown in Figure 2. Figure 2(a) represents the results of the calculation and

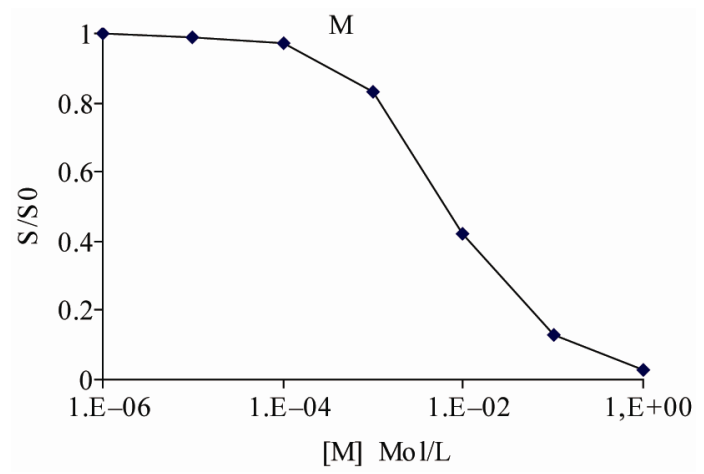

(a)

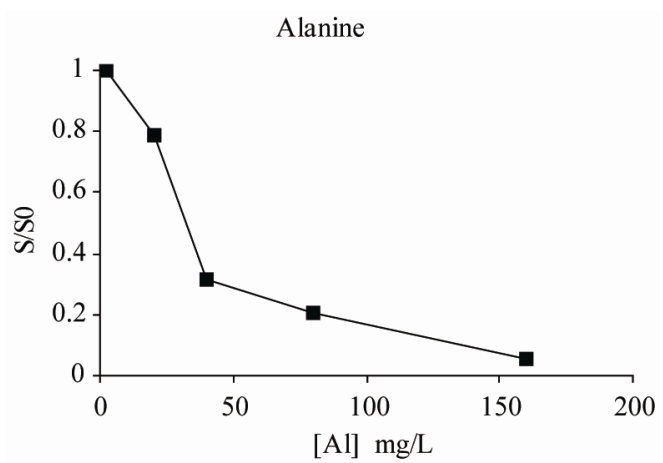

(b)

Figure 2. Chemiluminescence of ideal antioxidant $M$ in the oxidation by the Fenton reagent, $\left[\mathrm{Fe}^{2+}\right]=10^{-3}$ $\mathrm{mol} / 1,\left[\mathrm{H}_{2} \mathrm{O}_{2}\right]=10^{-4} \mathrm{~mol} / \mathrm{l}$. Along the ordinate axis: the ratio of the light sum for 30 seconds at a given concentration of test substance $\mathrm{S}$ to the light sum for 30 seconds for a pure Fenton solution S0, S/S0. (a) The calculation of the conditional material M. [M] concentration of substance, mol/l; (b) The experimenttal data on the chemiluminescence of alanine in Fenton solution. [Al] - the alanine concentration, $\mathrm{mg} / \mathrm{l}$. 


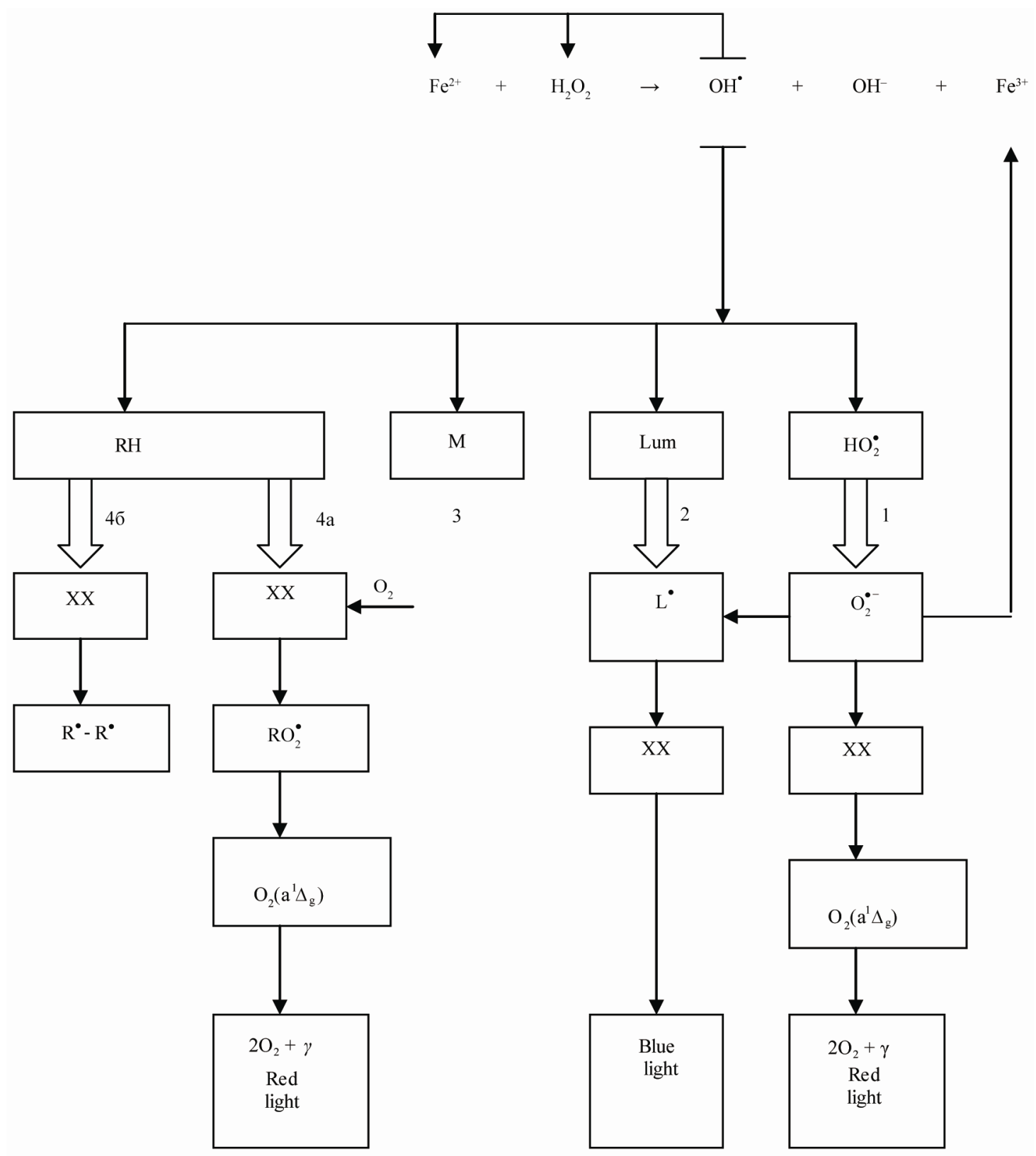

Scheme 1. Reactions in Fenton solution, leading to light emission. Numerals indicate the following cases: 1 . Only Fenton solution; 2. Luminol is added in Fenton solution; 3. Fenton solution with ideal antioxidant M; 4. Oxidation of organic matter RH in Fenton solution: a) in the presence of dissolved oxygen b) with a deficiency or complete absence of oxygen.

Figure 2(b) - the experimental data for alanine, an ideal antioxidant. The reaction constant $\mathrm{M}+\mathrm{OH}^{*}$ is taken equal to $10^{8}(\mathrm{~mol} \cdot \mathrm{s})^{-1}$.

Case 4. Oxidation of organic substances. A distinctive feature of the organic substances is the ability to continue the chain reactions. A typical scheme of oxidation of organic matter RH in water solution is presented in Table 6. The first active product of oxidation is radical $\mathrm{R}^{*}$ (reaction 26). Further, in the absence of oxygen, these radicals can be lost in interactions with each other (reac- tion 31). No luminescence will occur if the concentration of the substance introduced is high and it catches all the hydroxyl radicals. In the intermediate case there can be the situation considered for case 3 when not all hydroxyl radicals are used by RH substance and luminescence in channel 1 is preserved. This channel will be active in case of the lack of oxygen if $\left.\left[\mathrm{R}^{\circ}\right] \gg \mathrm{O}_{2}\right]$ (channel $4 \mathrm{~b}$, Scheme 1). If there is enough oxygen, then radical $\mathrm{RO}_{2}^{*}$ (reaction 27) is formed leading to singlet oxygen emergence (reaction 32). There is no interdiction implied on 
Table 6. Reactions of organic matter RH initiated by hydroxyl radicals in an aqueous solution.

\begin{tabular}{llc}
\hline No & \multicolumn{1}{c}{ Reaction } & $\mathrm{k},(\mathrm{mol} \cdot \mathrm{s})^{-1}[11]$ \\
\hline 26. & $\mathrm{RH}+\mathrm{OH}^{\bullet} \rightarrow \mathrm{R}^{\bullet}+\mathrm{H}_{2} \mathrm{O}$ & $10^{8}$ \\
27. & $\mathrm{R}^{\bullet}+\mathrm{O}_{2} \rightarrow \mathrm{RO}_{2}^{\bullet}$ & $10^{4}$ \\
28. & $\mathrm{RO}_{2}^{\bullet}+\mathrm{RH} \rightarrow \mathrm{ROOH}+\mathrm{R}^{\bullet}$ & $10^{6}$ \\
29. & $\mathrm{ROOH}+\mathrm{Fe}^{2+} \rightarrow \mathrm{Fe}^{3+}+\mathrm{OH}^{-}+\mathrm{RO}^{\bullet}$ & 100 \\
30. & $\mathrm{RO}+\mathrm{RO}^{\bullet} \rightarrow \mathrm{ROOR}$ & $10^{5}$ \\
31. & $\mathrm{R}^{\bullet}+\mathrm{R}^{\bullet} \rightarrow \mathrm{R}^{\mathrm{R}}$ & $10^{6}$ \\
32. & $\mathrm{RO}_{2}^{\bullet}+\mathrm{RO}_{2}^{\bullet} \rightarrow \mathrm{ROOR}+\mathrm{O}_{2}+\mathrm{O}_{2}\left(\mathrm{a}^{1} \Delta_{\mathrm{g}}\right)$ & $10^{7}$ \\
\hline
\end{tabular}

the formation of oxygen in a particular spin state for reaction 32. The ratio of the population probability for triplet and singlet states is determined by the rules of quantum mechanics and is 3:1. A dimer of singlet oxygen irradiates in the red spectrum (channel 4a, Scheme 1). The spectral composition of radiation has been tested with blue and red filters. The dependence of luminescence on the concentration of injected substances into channels $4 \mathrm{a}$ and $4 \mathrm{~b}$ will be different.

Case 4b. If there is no substance, $[\mathrm{RH}]=0$, the solution luminescence will be determined by channel 1 (pure Fenton solution). With the increase of RH concentration more radicals $\mathrm{OH}^{*}$ are consumed and luminescence diminishes until it completely disappears. The dependence of luminescence on the concentration of introduced substances will be similar to that of shown in Figure 2.

Case 4a. The addition of RH in low concentrations in Fenton solution has no effect on chemiluminescence. As $[\mathrm{RH}]$ increases, the luminescence caused by the reaction of the radicals $\mathrm{RO}_{2}^{*}$ becomes more intense. The total luminosity can increase tens times as large and reach maximum intensity. With the further increase of [RH], reaction $\mathrm{RO}_{2}^{\cdot}+\mathrm{RH}$ (reaction 28, Table 6) consuming radical $\mathrm{RO}_{2}^{\circ}$ begins to play its role and the emission decreases. When $[\mathrm{RH}]>>\left[\mathrm{RO}_{2}^{*}\right]$, the interaction of the radicals $\mathrm{RO}_{2}^{\cdot}$ with each other (reaction 32, Table 6) is very unlikely and the emission stops.

The results of calculation of S/S0 from the concentration of RH at different oxygen concentrations in solution are shown in Figure 3(a). The flash of luminescence is seen to decrease with the decrease of oxygen concentration and in the full absence of oxygen RH substance becomes almost a perfect anti-oxidant (compare Figure 2 (a)). The substantiality of calculation is confirmed by the experimental data for albumin (Figure 3(b)), when at a certain concentration of albumin luminescence reaches its maximum and then decreases.

\subsection{Individual Substance}

There may be cases, especially for low-molecular or-

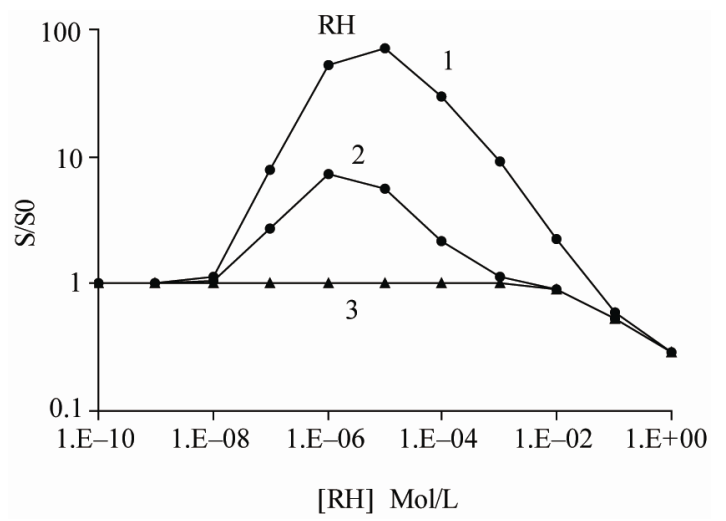

(a)

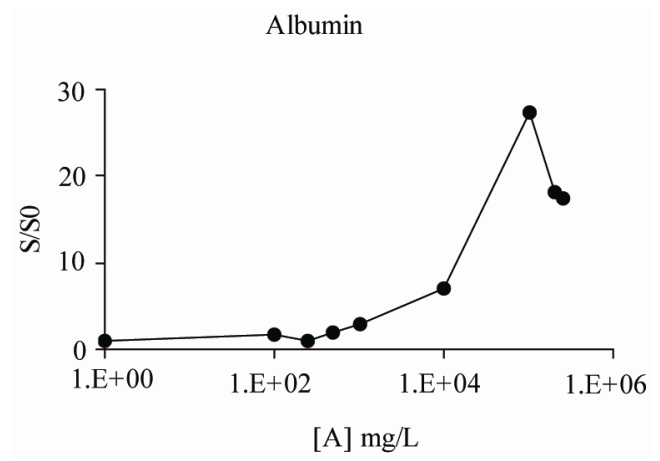

(b)

Figure 3. Chemiluminescence of organic matter $\mathrm{RH}$ in the oxidation by the Fenton reagent, $\left[\mathrm{Fe}^{2+}\right]=10^{-3} \mathrm{~mol} / \mathrm{l}$, $\left[\mathrm{H}_{2} \mathrm{O}_{2}\right]=10^{-4} \mathrm{~mol} / \mathrm{l}$. The ordinate axis: the ratio of the light sum for 30 seconds at a given concentration of the test substance to the light sum $\mathrm{S}$ for 30 seconds clear solution Fenton S0, S/S0. (a) The calculation for the conditional substance $\mathrm{RH}$. [RH] - concentration of substance, mol/l. The rate constants are given in Table 6 . The concentration of dissolved oxygen $\left.\left[\mathrm{O}_{2}\right]: 1\right) 10^{-4}$ $\left.\mathrm{mol} / \mathrm{l}, 2) 10^{-5} \mathrm{~mol} / \mathrm{l}, 3\right)\left[\mathrm{O}_{2}\right]=0$; (b) The experimental data on the chemiluminescence of albumin in Fenton solution. [A] - concentration of albumin, mg/l. The nonmonotoneness of presented dependence is associated with experimental errors.

ganic substances, when oxidation cannot be described by the scheme shown in Table 6. In this case the characteristics of the substance are to be taken into account. The oxidation of oxalic acid by hydroxyl radicals was studied in detail $[12,13]$. A simplified scheme of reactions contributing to the chemiluminescence is given in Table 7.

The particularity of this case is the formation of the radical $\mathrm{HO}_{2}^{*}$ (reaction 34) instead of $\mathrm{RO}_{2}^{*}$ and regeneration of oxalic acid (reaction 35). Radicals $\mathrm{HO}_{2}^{*}$ do not decompose oxalic acid at an appreciable rate, so with the increase of acid concentration the luminescence is not reduced. The calculated dependence of the chemiluminescence of oxalic acid on its concentration is presented in Figure 4(a). With the increase of oxalic acid concentration the luminescence is seen to increase. With 
Table 7. The reactions of oxalic acid affecting the chemiluminescence in Fenton solution.

\begin{tabular}{|c|c|c|}
\hline & Reaction & $\mathrm{k}(\mathrm{mol} \cdot \mathrm{s})^{-1}[13]$ \\
\hline 33. & $(\mathrm{COOH})_{2}+\mathrm{OH}^{\bullet} \rightarrow \mathrm{HOOC}-\mathrm{COO}^{\bullet}+\mathrm{H}_{2} \mathrm{O}$ & $1.4 \times 10^{6}$ \\
\hline 34. & $\mathrm{HOOC}-\mathrm{COO}^{\bullet}+\mathrm{O}_{2} \rightarrow \mathrm{HO}_{2}^{\bullet}+2 \mathrm{CO}_{2}$ & $1 \times 10^{8}$ \\
\hline 35. & $\mathrm{HOOC}-\mathrm{COO}^{\bullet}+\mathrm{HOOC}-\mathrm{COO}^{\bullet} \rightarrow(\mathrm{COOH})_{2}+2 \mathrm{CO}_{2}$ & $7.7 \times 10^{6}$ \\
\hline
\end{tabular}

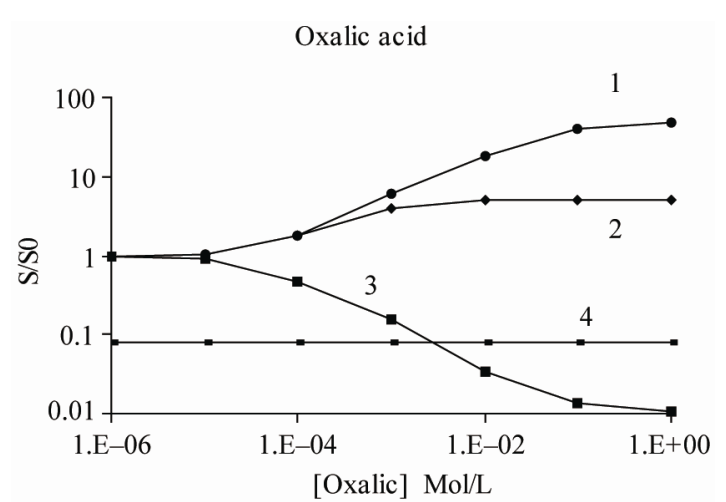

(a)

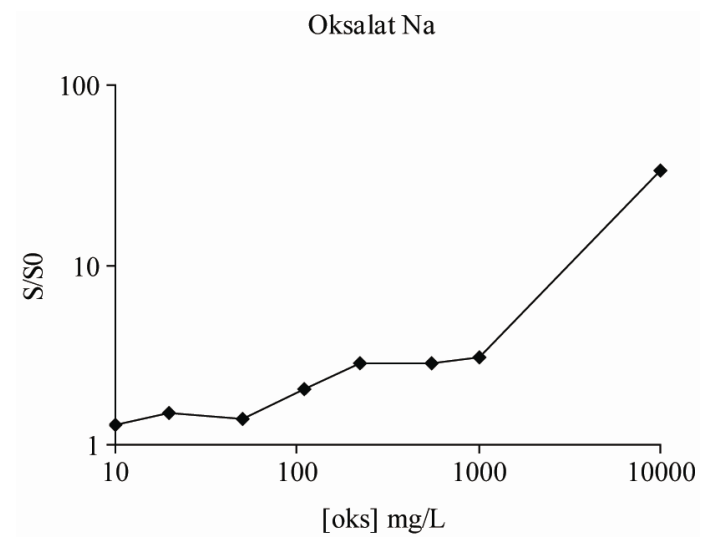

(b)

Figure 4. Chemiluminescence of oxalic acid in the course of oxidation by the Fenton reagent, $\left[\mathrm{Fe}^{2+}\right]=$ $10^{-3} \mathrm{~mol} / 1,\left[\mathrm{H}_{2} \mathrm{O}_{2}\right]=10^{-4} \mathrm{~mol} / \mathrm{l}$. S/S0 - see Figure 2. (a) The calculation is according to the reaction scheme shown in Table 7. [Oxalic] - concentration of oxalic acid, mol/l. 1) The concentration of dissolved oxygen $\left[\mathrm{O}_{2}\right]=10^{-4} \mathrm{~mol} / \mathrm{l} .2$ ) $\left[\mathrm{O}_{2}\right]=10^{-6} \mathrm{~mol} / \mathrm{l} .3$ ) $\left[\mathrm{O}_{2}\right]=0$ (no oxygen). 4) Chemiluminescence of Fenton solution due to the external background radiation. (b) The experimental data for sodium oxalate, [oks] - concentration of sodium oxalate, $\mathrm{mg} / \mathrm{l}$. The nonmonotoneness of presented data is related to experimental errors.

decreasing concentration of oxygen the intensity of chemiluminescence decreases and in the absence of oxygen oxalic acid behaves as an ideal antioxidant. If oxalic acid concentration is high in the absence of oxygen not only radicals $\mathrm{OH}^{\bullet}$ generated in the Fenton reaction are consumed but also those generated by external radiation background. Figure 4(a) shows that at concentrations of [Oxalic] $=10^{-2} \mathrm{~mol} / 1$ chemiluminescence yield (curve 3 ) is significantly below the level set by the background ra- diation (line 4).

The calculated dependence is qualitatively confirmed by the experiment with sodium oxalate (Figure $4(\mathbf{b})$ ). The main difference from the reaction schemes presented in Table 6 is that with increasing concentration of oxalic acid luminescence increases without passing through its maximum and decreases no further as shown in Figure 3. A higher yield of chemiluminescence compared to a pure Fenton solution is due to the fact that in Fenton solution most $\mathrm{OH}^{\bullet}$ radicals disappear during interactions with each other failing to transform into radicals $\mathrm{HO}_{2}^{*}$. When oxalic acid is added in a sufficiently high concentration, so that $[\mathrm{Oxalic}]>\left[\mathrm{OH}^{\bullet}\right]$, a major part of $\mathrm{OH}^{\bullet}$ radicals interacts with it and the radicals fully transform into radicals $\mathrm{HO}_{2}^{\circ}$. As the concentration of oxalic acid increases, the part of radicals $\mathrm{OH}^{\bullet}$ transformed into $\mathrm{HO}_{2}^{\bullet}$ also grows.

\subsection{The Form of Chemiluminescence Light Impulse}

Three cases are possible.

1a. Fenton solution. The maximum intensity is observed at first when the reaction rate is at its maximum. Taking into account the delay in the registration system the front duration can be $0.1-0.2$ seconds. The ferric iron that is formed consumes $\mathrm{O}_{2}^{--}$radicals and weakens the luminescence. When $20 \%-30 \%$ of the initial $\mathrm{Fe}^{2+}$ is converted to $\mathrm{Fe}^{3+}$, the luminescence practically stops.

1b. Luminol in neutral medium (pH 6 - 7). The situation is similar to a pure solution of Fenton. In Fenton solution with luminol the maximum light emission intensity is observed immediately after mixing the reagents. With increasing concentration of $\mathrm{Fe}^{2+}$ and $\mathrm{H}_{2} \mathrm{O}_{2}$ reaction rate increases and the amplitude of the light flash grows. The characteristic forms of impulse for this case are described [5].

2. Simple substance absorbing the hydroxyl radicals (ideal antioxidant $\mathbf{M}$ ). At first it can absorb practically all the hydroxyl radicals, so there will be no flash of light. Noticeable luminescence appears when the part of the substance is oxidized by radicals. The leading front of the pulse will be longer and can take $1-2$ seconds.

3. Organic matter RH. If it absorbs not all the hydroxyl radicals, the luminescence of Fenton solution itself will be seen. As the chain reaction starts, the oxidation products (radicals $\mathrm{RO}_{2}^{\bullet}$ ) are produced, and their in- 
teraction leads to the production of an additional singlet oxygen. It gives a new outbreak of light radiation, which is superimposed on the luminescence of Fenton solution. The delayed appearance of a new light impulse is determined by reaction rates 26 - 32 (Table 6) and can last 10 - 30 seconds, the flash duration being a few minutes. The amplitude of the second light flash can exceed by far the luminescence of Fenton solution. Calculated under the above-stated model luminosity of the mixture of Fenton solution with the RH substance is given in Figure 5. The graph shows the luminescence of a pure Fenton solution (peak 1) and luminescence formed in reactions $26-32$ (peak 2).

The form of the light radiation impulse, as shown in Figure 5, was really observed in the studies of chemiluminescence [2,3]. The emission maximum 1 and 2 can be interpreted as follows:

Maximum 1-glow caused by reactive oxygen species.

Maximum 2-the glow caused by free-radical processes in the sample (the formation of $\mathrm{RO}_{2}^{\bullet}$ ).

Not all organic substances during oxidation pass through a stage of formation of $\mathrm{RO}_{2}^{\bullet}$ type compounds. In this case maximum 2 is not observed. For example, in oxalic acid oxidation $\mathrm{HO}_{2}^{\circ}$ is formed instead of radical $\mathrm{RO}_{2}^{\bullet}$ (see Table 7). Radical $\mathrm{RO}_{2}^{\bullet}$ plays a minor part in the oxidation of ascorbic acid. Thus, the fact of appearance or absence of maximum 2 (Figure 5) enables to draw conclusions about the reaction mechanism. In general case, the oxidation scheme of the test substance is necessary to be considered for a detailed analysis of the results of the chemiluminescence oxidation.

\subsection{Evaluation of Properties of a Certain Antioxidant with the Fenton Reaction}

Ascorbic acid can be considered as an example. Researchers repeatedly note that ascorbic acid possesses both antioxidant and prooxidant properties [14-16]. The scheme of ascorbic acid oxidation is presented in Table 8. The characteristics of reactions are taken from ref. [15, 17]. Ascorbic acid in an aqueous solution dissociates in two steps (reactions 36 and 37, Table 8). At pH values typical for biological objects (pH 6 to 7.5), ascorbic acid remains in solution as ions $\mathrm{AscH}^{-}$(more than 99\%).

The primary oxidation product of $\mathrm{AscH}^{-}$is radical $\mathrm{Asc}^{--}$(reaction 38, Table 8). A feature of ascorbic acid is that neither the ion $\mathrm{AscH}^{-}$nor radical $\mathrm{Asc}^{\bullet-}$ interacts with oxygen [15]. Only ion $\mathrm{Asc}^{2-}$ interacts with oxygen (reaction 40), forming an ion-radical $\mathrm{O}_{2}^{--}$. Two radicals of $\mathrm{Asc}^{\bullet-}$ transform to initial ion and DHA (dehydroascorbic acid, reaction 39). DHA is further oxidized by oxygen to form various compounds, including a prooxidant such as

Table 8. Oxidation reaction of ascorbic acid $\mathrm{AscH}_{2}$. $\mathrm{AscH}^{-}$and $\mathrm{Asc}^{2-}$ are the products of the first and second stages of dissociation of ascorbic acid. Asc ${ }^{\bullet-}$ is ascorbate ion-radical, DHA dehydroascorbic acid.

\begin{tabular}{|c|c|c|}
\hline No & Reaction & $\begin{array}{l}\text { The equilibrium constant, The } \\
\text { rate constant }[15,17]\end{array}$ \\
\hline 36. & $\mathrm{AscH}_{2} \leftrightarrow \mathrm{AscH}^{-}+\mathrm{H}^{+}$ & $\mathrm{pK}_{\mathrm{a} 1}=4.1$ \\
\hline 37. & $\mathrm{AscH}^{-} \leftrightarrow \mathrm{Asc}^{2-}+\mathrm{H}^{+}$ & $\mathrm{pK}_{\mathrm{a} 2}=11.8$ \\
\hline 38. & $\mathrm{AscH}^{-}+\mathrm{OH}^{\bullet} \rightarrow \mathrm{Asc}^{\bullet-}+\mathrm{H}_{2} \mathrm{O}$ & $\mathrm{k}_{3}=1.1 \times 10^{10}(\mathrm{~mol} \cdot \mathrm{s})^{-1}$ \\
\hline 39. & $2 \mathrm{Asc}^{\bullet-}+\mathrm{H}^{+} \rightarrow \mathrm{AscH}^{-}+\mathrm{DHA}$ & $\mathrm{k}_{4}=1.4 \times 10^{5}(\mathrm{~mol} \cdot \mathrm{s})^{-1}$ \\
\hline 40. & $\mathrm{Asc}^{2-}+\mathrm{O}_{2} \rightarrow \mathrm{Asc}^{\bullet-}+\mathrm{O}_{2}^{\bullet-}$ & $\mathrm{k}_{5}=100(\mathrm{~mol} \cdot \mathrm{s})^{-1}$ \\
\hline
\end{tabular}

$\mathrm{RH}+$ Fenton

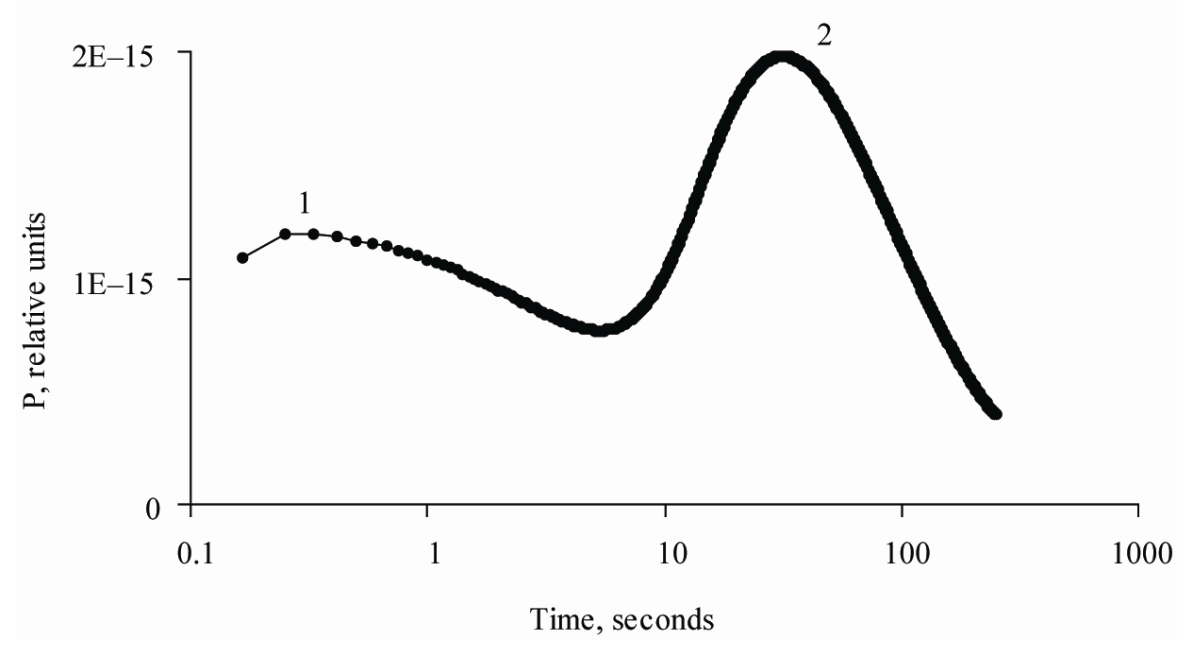

Figure 5. The intensity of chemiluminescence $\mathrm{P}$ of organic matter $\mathrm{RH}$ in Fenton solution. $\left[\mathrm{Fe}^{2+}\right]=10^{-3} \mathrm{~mol} / \mathrm{l},\left[\mathrm{H}_{2} \mathrm{O}_{2}\right]=10^{-4} \mathrm{~mol} / \mathrm{l},[\mathrm{RH}]=10^{-4} \mathrm{~mol} / 1$. The figures denote: 1$)$ The flash of chemiluminescence due to reactions in a pure Fenton solution by oxygen active forms; 2) Chemiluminescence of singlet oxygen formed in reaction 32 (Table 6) due to free radicals. 
oxalic acid.

Calculated dependence of $\mathrm{S} / \mathrm{S} 0$ on concentrations of ascorbic acid without regard to the products of DHA transformation is presented in Figure 6 for two cases: in oxygen medium and in the one without. It is evident that without oxygen S/S0 monotonically decreases with increasing [Asc] (curve 2), and in the presence of oxygen for $[$ Asc $]>10^{-3} \mathrm{~mol} / \mathrm{l}$ ratio $\mathrm{S} / \mathrm{S} 0$ begins to increase (curve 1). The increase is due to formation of superoxide ion-radical $\mathrm{O}_{2}^{--}$. In the course of reactions in Fenton solution, this radical can, although with a low probability, transform into a hydroxyl radical $\mathrm{OH}^{\bullet-}$. In this case, ascorbic acid will absorb secondary radicals initiated by its oxidation. At the concentration of [Asc] up to $1 \mathrm{~mol} / \mathrm{l}$ the antioxidant effect will occur, although the probability of suppression of radicals with increasing concentration of acid in solution, saturated by air, will decrease.

The experimentally obtained dependence S/S0 on a wide range of concentrations of ascorbic acid [Asc] is shown in Figure 7. Measurements were performed for two cases: 1) the solution contains oxygen dissolved in natural conditions, 2) solution is depleted of oxygen by adding $0.1 \mathrm{ml}$ of $\mathrm{Na}_{2} \mathrm{SO}_{3}$ solution at a concentration of $3.2 \mathrm{~g} / \mathrm{l}$. In a separate experiment it has been found that the introduction of $\mathrm{Na}_{2} \mathrm{SO}_{3}$ has no influence on luminescence of Fenton solution. With the help of color filters it has been identified that chemiluminescence occurs in the red spectrum.

In the presence of oxygen (curve 1) and at a low concentration of [Asc] value $\mathrm{S} / \mathrm{S} 0$ equals to 1 , which may be primarily due to the small contribution of secondary reactions (initiated by the interaction $\mathrm{AscH}^{-}+\mathrm{OH}^{\bullet}$ ) to the general flow of radicals generated in the Fenton reaction. With increasing of [Asc] ratio S/S0 exceeds 1, then it decreases with increasing [Asc] and becomes less than 1 . When $\mathrm{S} / \mathrm{S} 0<1$, we can see the marked antioxidant properties of the substance introduced in Fenton solution. Value $\mathrm{S} / \mathrm{S} 0>1$ indicates the number of secondary radicals formed in reactions with introduced substance to exceed the number of primary ones, i.e. chain reaction takes place. In case of lack of oxygen (curve 2) the S/S0

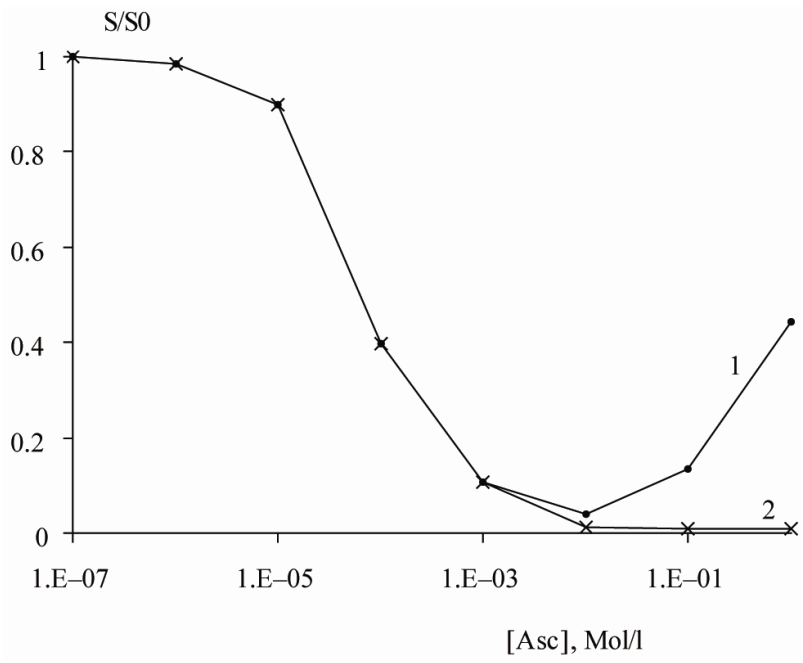

Figure 6. The ratio dependence of the light sum during $30 \mathrm{sec}-$ onds for Fenton solution with ascorbic acid $\mathrm{S}$ to the light sum for a pure Fenton solution S0 (S/S0) on the concentration of ascorbic acid, [Asc], mol/l. 1) solution, saturated by oxygen, $\left.\left[\mathrm{O}_{2}\right]=2 \times 10^{-4} \mathrm{~mol} / \mathrm{l}(7 \mathrm{mg} / \mathrm{l}), 2\right)$ without oxygen. When [Asc] $<10^{-3} \mathrm{~mol} / \mathrm{l}$ curves 1 and 2 are the same.

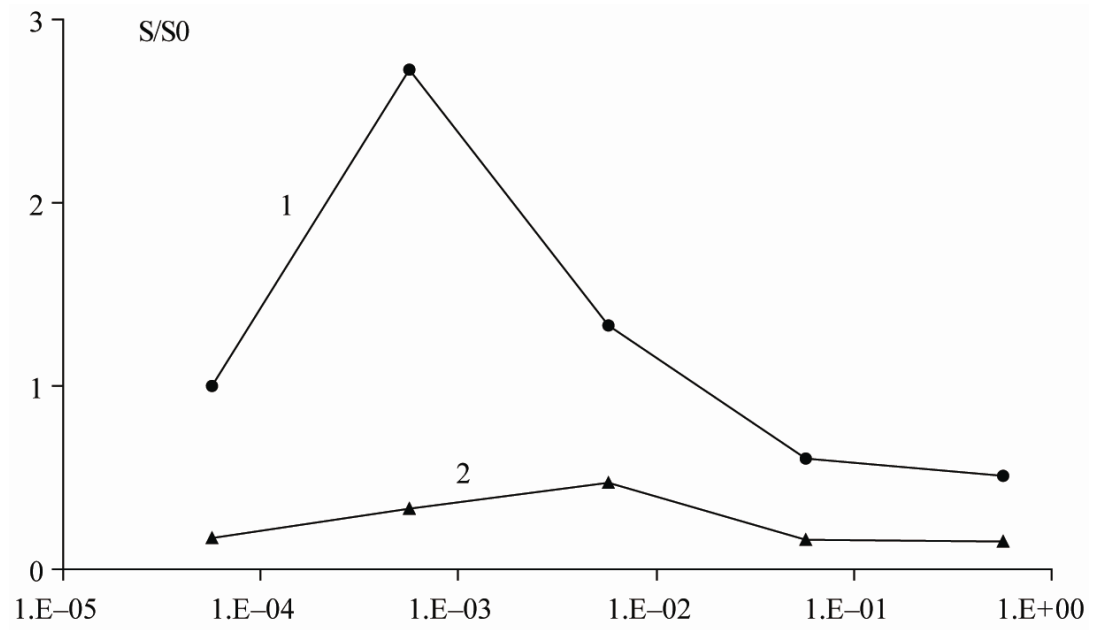

[Asc] Mol/L

Figure 7. Chemiluminescence of ascorbic acid in the oxidation by the Fenton reagent, $\left[\mathrm{Fe}^{2+}\right]=10^{-3} \mathrm{~mol} / 1,\left[\mathrm{H}_{2} \mathrm{O}_{2}\right]=10^{-4} \mathrm{~mol} / \mathrm{l} . \mathrm{S} / \mathrm{S} 0$ - see Figure 6. [Asc]-concentration of ascorbic acid, mol/l. Errors of ratio $\mathrm{S} / \mathrm{S} 0$ do not exceed $5 \%$. 1) There is oxygen dissolved in vivo in the solution; 2) Solution is depleted of oxygen by the addition of 0.1 $\mathrm{ml}\left[\mathrm{Na}_{2} \mathrm{SO}_{3}\right]=3.2 \mathrm{~g} / \mathrm{l}$. 
is less than 1 for all concentrations of ascorbic acid, which means that the ascorbic acid itself is an antioxidant.

Prooxidant properties were observed in $[14,15]$ at the concentration of ascorbic acid of approximately $10^{-3}$ $\mathrm{mol} / \mathrm{l}$, which is close to the concentration at which the maximum $\mathrm{S} / \mathrm{S} 0$ is reached in Figure 7 for the solution containing oxygen. The authors of $[14,15]$ report ascorbic acid at concentrations of $10^{-3} \mathrm{~mol} / \mathrm{l}$ to have different properties compared to larger concentrations. In terms of Scheme 1 the properties of the acid do not change with concentration, but the ratio of individual channels of reactions occurring in course of Asc oxidation is changed.

According to the mechanism of its oxidation, ascorbic acid itself cannot be prooxidant, which is confirmed by other studies [18]. The results of the present study suggest that the prooxidant properties do not appertain to the ascorbic acid, but to products oxidized by DHA oxygen, among which can be oxalic acid. Figure 4 shows that oxalic acid in the presence of oxygen has prooxidant properties. Reduction of the prooxidant activity observed experimentally in $[\mathrm{Asc}]>10^{-3} \mathrm{~mol} / 1$ in the presence of oxygen can be attributed to the expenditure of dissolved oxygen in reaction 40 , and perhaps its shortage as the concentration of oxygen in the water is about $10^{-4} \mathrm{~mol} / \mathrm{l}$, while [Asc] is more than $10^{-3} \mathrm{~mol} / 1$.

The form of the impulse also helps to draw the conclusion on the composition of the secondary radicals. If the secondary radicals are of complex sedentary nature $\mathrm{RO}_{2}^{\bullet}$, which are discharged into reaction 32 (Table 6) with the formation of singlet oxygen, a flash of light should have the form shown in Figure 5, i.e. the delay in appearance of light - tens of seconds, and duration of the light pulse - $\mathrm{a}$ few minutes. If the secondary radicals are highly movable $\left(\mathrm{HO}_{2}^{\bullet}, \mathrm{O}_{2}^{--}\right)$, the flash of light will be short, less than 30 seconds. Such flash is observed in oxalic acid and at all concentrations of ascorbic acid. Such radicals as $\mathrm{RO}_{2}^{\bullet}$ might yet form during the decomposition of DHA. However, their formation is extended in time, is not bound by the time of introducing the components of the Fenton reagent, and cannot be detected by the applied technique of chemiluminescence. Thus, the analysis of the properties of antioxidants in Scheme 1 allows revealing the features of the tested substances.

\section{CONCLUSIONS}

1) If 30 seconds have been selected as radiation registration time, the preferred concentration of Fenton solution reagent is $\left[\mathrm{Fe}^{2+}\right]=10^{-3} \mathrm{~mol} / 1,\left[\mathrm{H}_{2} \mathrm{O}_{2}\right]=10^{-4} \mathrm{~mol} / 1$.

2) The radiation background produced by cosmic rays and other sources induce luminescence which is registered by luminometer and is to be taken into account.
3) The main radiant product in the solution of Fenton is a dimer of singlet oxygen. The glow of the solution is stopped when the ferric iron that is formed absorbs almost all radicals $\mathrm{O}_{2}^{--}$. The same mechanism of luminescence quenching operates for luminol in a neutral medium.

4) The luminescence of organic substances relates to radicals $\mathrm{RO}_{2}^{\circ}$. No luminescence appears in a non-oxygen solution. In the presence of oxygen with an increasing concentration of $\mathrm{RH}$ the reaction $\mathrm{RH}+\mathrm{RO}_{2}^{\bullet} \rightarrow \mathrm{R}^{\bullet}$ $+\mathrm{ROOH}$ begins to dominate and the emission stops.

5) Depending on the mechanism of the process, chemiluminescence is grouped in different time intervals after the injection of all the substances. In the period from 0 to 30 seconds the glow is caused by reactive oxygen species. During the time period from 30 seconds to several miutes it is due to the emission of free-radical reactions occurring in the sample.

6) Observed for a single substance oxidant and prooxidant properties are caused by the same reaction mechanism. At high concentration the intermediate radicals, the reaction products are absorbed by the initial substance and antioxidant properties are observed. At low concentrations of introduced substances intermediate radicals are preserved and prooxidant properties are observed.

7) Prooxidant properties of ascorbic acid observed in some cases are associated with the DHA oxidation products with oxygen. In the absence of oxygen the prooxidant effect does not occur.

\section{REFERENCES}

[1] Vasil'ev R.F. (1966) Chemiluminescence in solutions. Advances in Physical Sciences, 89, 409-436.

[2] Vladimirov, Y.A. and Proskurina, E.V. (2009) Free radicals and cell chemiluminescence. Biochemistry (Moscow), 49, 341-388.

[3] Vladimirov, Y.A. and Potapenko, A.Y. (1989) Physicochemical bases of photobiological processes. Higher School, Moscow.

[4] Roshchupkin, D.I., Belakina, N.S. and Murin, A.A. (2006) Enchanged luminal chemiluminescence of rabbit polimorphonuclear leukocytes: The nature of oxidants that directly cause oxidation of luminal. Biophysics, 51, 99197. doi:10.1134/S000635090601012X

[5] Aristova, N.A., Ivanova, I.P., Trofimova, S.V., Knyazev, D.I. and Piskarev, I.M. (2011) Luminol-dependent luminescence that accompanies the reaction of Fenton. http://zhurnal.ape.relarn.ru/articles/2011/008.pdf

[6] Formazyuk, V.E., Gorshkov, T.N. and Sergienko, V.I. (2001) A method for determining the antioxidant activity of substances. Patent of Russia 2163021.

[7] Pikayev, A.K. and Kabakci, S.A. (1982) Reactivity of the primary products of water radiolysis. Energoatomizdat, Moscow. 
[8] Bugayenko, L.T., Kuzmin, M.G. and Polak, L.S. (1988) High energy chemistry. Khimiya, Moscow.

[9] Kulagin, Y.A., Shelepin, L.A. and Yarygina, V.N. (1994) Kinetics of processes in the gas media containing metastable oxygen. Lebedev FIAN, 218, 166-227.

[10] Ivanova, I.P., Knyazev, D.I., Kudryavtsev, Y.V., Chuprov, A.D. and Trofimova, S.V. (2011) Oxidation of lipids and proteins in the lens and blood plasma of rats during aging. Advanced Technologies in Medicine, 3, 16-21.

[11] Sarayeva, V.V. (1991) Oxidation of organic compounds under the influence of ionizing radiation. Moscow State University Publishing House, Moscow.

[12] Kim, J.-C., Kim, D.-H., Kim, Y., Makarov, I.E., et al. (1999) Deep decomposition of formic acid in aqueous solutions at the electron-beam exposure. High Energy Chemistry, 33, 413-417.

[13] Aristova, N.A., Mokina, T.S. and Piskarev, I.M. (2003) Oxidation of formic and oxalic acids in the electrodeless electrochemical reaction. Journal of General Chemistry (Russia), 5, 756-760.

[14] Schafer, F.Q., Kelley, E.E. and Buettner, G.R. (2003) Oxidative stress and antioxidant intervention. Critical re- views of oxidative stress and aging: Advances in basic science. In: Cutler, R.G. and Rodriguez, H., Eds., Diagnostics and Intervention. World Scientific, New York, 849-869.

[15] Buettner, G.R. and Jurkiewicz, B.A. (1996) Catalitic metals, ascorbate and free radicals: Combinations to avoid. Radiation Research, 145, 532-541. doi:10.2307/3579271

[16] Ryabchenko, N.I., Ryabchenko, V.I., Ivannikov, B.P., Dzikovskaya, L.A., Sinkova, R.V., Grosheva, I.P., Degtyarev, E.S. and Ivanova, T.I. (2010) Antioxidant and prooxidant properties of ascorbic acid, dihydro quercetin and mexidol in radical reactions induced by tue ionizing radiation and chemical reagents. Radiation Biology and Radioecology, 50, 186-194.

[17] Bors, W. and Buettner, G.R. (1977) The vitamin C and its reactions. The vitamin $\mathrm{C}$ in health and disease. Marcel Dekker Inc., New York, 75-94.

[18] Carr, A. and Frei, B. (1999) Does vitamin C act as pro-oxidant under physiological conditions. The FASEB Journal, 13, 1007-1024.

\author{
Abbreviations \\ Lum-luminol \\ $\mathrm{L}$ - - luminol's radical \\ $\mathrm{M}$-ideal antioxidant \\ S0-light sum of chemiluminescence for pure Fenton \\ solution for 30 seconds
}

S-light sum of chemiluminescence for 30 seconds at a given concentration of test substance in Fenton solution Al_alanine

A-albumin

Oxalic_oxalic acid

Oks - oksalat

Asc_ascorbic asid 